\title{
VIOLÊNCIA ENTRE PARCEIROS ÍNTIMOS (VPI): PROBLEMA E SINTOMA NO PANORAMA DAS VIOLÊNCIAS SOBRE AS MULHERES
}

Centro de Investigação e Intervenção Educativas, FPCEUP.

\section{Resumo}

A violência entre parceiros íntimos (VPI) tem sido, por vezes, reconhecida como um problema que afeta mulheres e homens e põe em risco a democracia. A VPI é também um sintoma no panorama amplo das violências sobre as mulheres, que nem sempre têm sido reconhecidas e que têm sido veladas sob noções de "discriminação» ou "desigualdade». Depois de refletir acerca da violência social, este artigo suporta-se na análise de documentos-chave para abordar a VPI, como forma específica de violência sobre as mulheres, entre outras que ocorrem no espaço familiar, em Portugal e no contexto Europeu. O argumento dirige-se à construção de formas de vida amigas-de-mulheres-e-homens que corporizem uma democracia mais autêntica.

Palavras-chave: violência social; violência entre parceiros íntimos; formas de vida amigas-de-mulheres-e-homens.

\section{Abstract \\ Intimate partner violence (IPV): A problem and a symptom in the panorama of violence(s) over women \\ Intimate partner violence (IPV) has been sometimes recognized as a problem that affects women and men and undermines democracy. Known as problem, IPV is also a symptom in the panorama of violence(s) over women, which not always have been acknowledged and have been veiled under notions such as «discrimination» or «inequality». After reflecting upon these interrelated violence(s), this article builds on the analysis of key documents to reflect upon IPV in Portugal, in the European context, as a specific form of violence among others within the family space. The argument is set on the viable utopia of nonviolent women-and-men-friendly life construction, the search for a more authentic democracy.}

Keywords: social violence; intimate partner violence; women-and-men-friendly modes of life.

\section{Résumé}

La violence entre partenaires intimes (VPI): Un problème et un symptôme dans le panorama des violence(s) sur les femmes

La violence entre partenaires intimes (VPI) a été reconnue quelque fois comme un problème qui affecte hommes et femmes et met en danger la démocratie. Reconnu comme problème, VPI est aussi un symptôme dans le panorama des violences sur les femmes, que

1 Centro de Investigação e Intervenção Educativas, FPCEUP. Instituto Paulo Freire de Portugal. Associação ESPAÇOS: Projetos Alternativos de Mulheres e Homens. eunicemacedo 58@hot mail.com 
n'ont pas toujours été reconnues et qu'ont été voilée sous les notions de "discrimination» ou «inégalité». Après avoir réfléchi sur la violence sociale, cet article analyse des documents-clés pour réfléchir sur le VPI au Portugal dans le contexte européen, comme mode spécifique de violence dans la famille, entre autres. L'argument réside dans l'utopie viable de construction de formes de vie amis-de-femmes-et-hommes; la recherche d'une démocratie plus authentique.

Mots-clés: violence sociale; violence entre partenaires intimes; formes de vie amis-de-femmes-et-hommes.

\section{Introdução}

Além de desvendar formas de violência social sobre as mulheres, como cenário para a violência entre parceiros íntimos, este artigo situa uma visão sociológica implicada na intervenção social (Brewer, 2004). Busca a construção de ambientes inclusivos de mulheres e homens, com base no reconhecimento como sujeitos únicos (Bernstein, 1996) situados em relações de poder que exigem mudança.

Sob a premissa que as várias formas de violência sobre as mulheres põem em risco cidadania e democracia, discute-se o termo «mulher» para enfatizar a diversidade interna desse grupo social; questionam-se formas de violência sobre as mulheres no espaço público e (mais) privado da família, dada a replicação frequente das relações de poder. $\mathrm{O}$ uso da expressão «violência sobre as mulheres» acentua a localização em subordinação, desvalorização e falta de reconhecimento. Tendo em conta o (mau) exemplo da VPI, busco formas possíveis duma democracia mais autêntica, num horizonte de vida amiga-de-mulheres-e-homens com comunicação e valorização da diversidade. Isto implica melhoramento das localizações estruturais de poder (Young, 2002) com implicação individual e coletiva.

Com base em documentos-chave que incluem a violência entre parceiros íntimos na UE, o artigo reflete acerca da violência sobre as mulheres no espaço familiar. Examinam-se as dificuldades mais prementes para enfrentar o problema e apontam-se possíveis respostas, frequentemente associadas a recursos, a diferentes níveis da tomada de decisão política. A situação portuguesa ilustra um pouco do que está a ser feito nesta luta.

Desde os anos 1990, a emergência da violência contra as mulheres como preocupação política, social e académica é ilustrada por largo número de publicações, em diversos campos (Auchter e Moore, 2013). Para referir alguns exemplos nacionais, AAVV (1998) foca a violência na conjugalidade, Nelson Lourenço e Manuel Lisboa (1991), Lourenço, Lisboa e Elza Pais (1997) e, mais recentemente, Isabel Dias (2010) analisam o problema do ponto de vista jurídico. Nesta década, estudos na linha do movimento feminista, situam a chamada violência «doméstica» como violação dos direitos humanos (Campos, 2004; Monteiro, 2005; Azambuja e Nogueira, 2008). Outros trabalhos analisam os custos económicos deste fenómeno social (Lisboa, Vicente, Carmo e Nóvoa, 2003) ou relacionam violência 
e saúde pública (Lisboa, Barroso, Marteleira, 2003; Lisboa, Vicente e Barroso, 2005). A prevalência da perpetração e vitimização em diferentes tipos de abuso no relacionamento íntimo juvenil, incluindo entre jovens universitários/as é também analisada em diversos trabalhos (Machado, Matos e Moreira, 2003; Paiva e Figueiredo, 2004; Caridade e Machado, 2006). Sofia Neves (2008), do campo da Psicologia Feminista Crítica, acentua o caráter genderizado do poder e da violência, num enquadramento patriarcal. Fazendo a ponte entre reflexão e ativismo social, outras obras propõem a intervenção feminista pela arte (Magalhães, 2010). No contexto internacional, entre inúmeras publicações, os números mais recentes da revista Violence Against Women analisam o impacto da VPI no bem-estar económico das mulheres (Adams, Tolman, Bybee, Sullivan, e Kennedy, 2012); discutem a violência no namoro (Lopez, Chesney-Lind e Foley, 2012) ou propõem a construção de novas narrativas sobre as mulheres como sobreviventes resistentes (Arnold e Ake, 2013; Rivas, Kelly e Feder, 2013).

\section{Violência(s) sobre as mulheres: cenários para a violência entre parceiros íntimos (VPI)}

Atendendo às interligações entre o espaço "público» e "privado», utiliza-se o conceito de «violência social» para referir a violência no espaço social mais amplo. A «violência social» é vista como um processo específico que releva da cultura e não da herança biológica; um processo, complexo e multidimensional, associado à vida no coletivo e qualitativamente distinto da violência individual (Gonçalves, 1985) que pode incoporar diversas dimensões de opressão estrutural (Young, 2002), ligadas às questões de (má) redistribuição e (falta) de reconhecimento, como desenvolvo adiante. No que diz respeito à «violência no espaço familiar» - a designada "violência doméstica» - que incorpora processos tão diversos como o abuso de crianças, jovens e idosos, e incusivamente sobre os homens (Casimiro, 2013) este artigo aborda apenas a "violência entre parceiros íntimos» (VPI) (Adams, Tolman, Bybee, Sullivan e Kennedy, 2012; Auchter e Backes, 2013).

As manifestações da violência social muitas vezes dependem de modalidades de discriminação cruzada. Afetando de forma diferente mulheres distintas, tornam-se tanto mais graves quanto mais marcadas as suas localizações de fragilização. Dimensões como etnia, deficiência, falta de reconhecimento cultural e falta de recursos sociais e económicos, podem intersecionar-se na acentuação da violência social, sendo também enganoso supor que uma mulher com pertença a grupos dominantes não está sujeita a quaisquer formas de violência.

Numa perspetiva desunificadora, este ponto analisa a violência social, identificando um conjunto de manifestações: sexismo da linguagem e homogeneização; heteronormatividade, hipersexualização e assédio; e produção e reprodução, como cenário facilitador da emergência de violência entre parceiros íntimos (VPI), analisada adiante. 


\section{Sexismo da linguagem e homogeneização}

Como forma de violência sobre as mulheres, o sexismo da linguagem reflete sociedades androcêntricas, que nos colocam em subordinação, e reproduz o poder hegemónico masculino. $\mathrm{O}$ uso da palavra Homem para referir a humanidade como um todo é conhecido por fazer recurso ao universal neutro (Lister, 1997), escondendo um sujeito universal masculino e naturalizando a invisibilidade social das mulheres, como não-sujeitos (Macedo, 2009). Também a utilização do conceito Mulher tem estado presente como conceito-chave em alguns estudos feministas, como forma de sexismo da linguagem que acarreta homogeneização.

Iris Young (1997) captou a desmontagem de classe social por Sartre para a desunificação do conceito mulher como representativo duma categoria social. Acentua que a pertença a uma série é assumida de forma distinta por cada pessoa, que pode partilhar com outras a experiência de objetos, estruturas e práticas por relação com o trabalho, a troca e o consumo. Esta experiência é informada por uma história de relações de género que também informam a interpetação individualizada dos processos sociais, constituindo uma areia na engrenagem de uma ordem social baseada em desigualdades. É, por isso, que a homogeneização das mulheres sob uma identidade única - normalmente de acordo com o modelo da mulher branca, heterossexual, de classe média, culta, católica, em plena posse das suas capacidades físicas e mentais e possuidora de atributos como beleza e sensualidade - constitui violência social naturalizada sobre as mulheres. Negando todas as outras, a homogeneização não permite a expressão da voz - conceito sociológico que se reporta à especificidade das nossas histórias, perspetivas, desejos e necessidades, percursos e orientações - que deveria constituir ponto de partida para a interação e reclamação pública (Young, 2002).

Permitindo acentuar a heterogeneidade, "mulheres» é um termo mais adequado à fragmentação do sujeito da cidadania na modernidade tardia (Macedo e Araújo, 2009), abre lugar à emersão do sujeito-mulher (Marijke Koning, 2005) ou do sujeito-mulheres (Magalhães, 2012). Mulheres é instituinte de um paradigma «novo» de reconhecimento em que as diferenças não são constituídas em desigualdade. «Reconhecimento» pode ser visto como ferramenta contra a heteronormatividade e outras formas de violência social sobre as mulheres.

\section{Heteronormatividade, hipersexualização e assédio}

A construção da heteronormatividade como «modelo de vida» e a sua inculcação é outro exemplo de violência social. Ao desvalorizar ou situar em negação outras formas de orientação afetiva não-heterossexual, pode ter consequências drásticas, podendo incluir secretismo, vergonha e/ou inadequação nessas mulheres - incluindo as jovens. Esta forma de violência pode ser acoplada às relações de poder genderizadas, no quadro de uma agenda androcêntrica que só reco- 
nhece os homens como dignos de afeição e atração sexual. Amy Hequembourg, Jennifer Livingston e Kathleen Parks (2013), que apresentam uma análise viva da vitimização sexual e dos seus riscos entre mulheres lésbicas e bissexuais, mostram que o abuso é cometido principalmente por homens e, muitas vezes, depois das mulheres se assumirem.

A violência da hipersexualização social, principalmente das mulheres jovens, cujos corpos são há décadas utilizados como adereços para a venda de produtos (para homens e mulheres), e domesticados para corresponderem aos ideais de beleza e sensualidade «apropriados», objetificando, deixa também na margem da não-identificação todas as que não se ajustam ao «modelo». Contraditoriamente, este mundo social hipersexualizado continua a penalizar as mulheres jovens que exploram a sua sexualidade, que ficam sob pressão do chamado «bom» comportamento, da repressão e silenciamento do afeto e sexualidade. Estes limites aos direitos sexuais das mulheres aprisionam-nos sob uma quasicidadania-sexual-recatada (Macedo, 2012a, 2012b).

O assédio sexual e moral também constitui violência social, imposta em diferentes áreas da vida das mulheres, especialmente em locais de trabalho onde ainda é usado como forma de regulação. Não cabendo aqui o seu aprofundamento, esta questão tem sido sumamente estudada em contexto nacional e internacional (Baker, 2008, Ferreira, 2005, Felker, 2006, Freitas, 2001) e objeto de preocupação da Comissão para a Cidadania e a Igualdade de Género (CIG) e da Comissão para a Igualdade no Trabalho e no Emprego (CITE). Tal como tem sido argumentado em diversos estudos, de que citei apenas um pequeníssimo número, a questão do assédio continua a afetar a liberdade de escolha das mulheres e a assunção duma sexualidade verdadeiramente gratificante, como direito.

\section{Produção e reprodução}

Há alguns anos, a expectativa social do trabalho produtivo remunerado e reprodutivo não remunerado das mulheres, por acumulação e conciliação, tem passado no debate académico e político. É exemplar da intersecção entre os espaços público e familiar no reforço da violência sobre as mulheres. A nossa entrada no mercado de trabalho, em diferentes períodos e por relação com diferentes contextos históricos, não surgiu do reconhecimento das nossas necessidades, capacidades e/ou direitos de cidadania, mas para preencher cargos deixados em aberto pelos homens (Macedo e Santos, 2009); por exemplo, pela partida e morte, na Segunda Guerra Mundial, se pensarmos na Europa; e na chamada Guerra Colonial, no caso Português.

Do lado das mulheres, e face às reclamações feministas, a entrada no mercado de trabalho constituiu condição de cidadania. Dando acesso a bens de consumo e reduzindo a sua dependência económica, contribuiu para o aumento da 
autonomia face aos homens (Lister, 1999). No entanto, a violência económica continua a ser exercida sobre muitas mulheres, como violência baseada no género. Como muitas outras, atualmente, as mulheres libanesas experimentam abuso económico, na retenção dos seus salários, na participação restrita na força de trabalho, nos limites nas decisões de compra, nas leis e práticas de herança. Muitas toleram esse abuso para evitarem outros e garantirem a estabilidade da família (Usta, Nisrine e Habib, 2013).

$\mathrm{O}$ acesso e participação das mulheres no mercado de trabalho, desenhado por e para homens, não é livre de violência. Para serem reconhecidas, muitas mulheres tiveram/têm que estabelecer modelos relacionais masculinos de trabalho e liderança (Macedo e Santos, 2009). Por outro lado, a expectativa social de acumulação das tarefas reprodutivas (serviço doméstico, assistência à família, reprodução da espécie), com pouco ou nenhum reconhecimento social, com o trabalho produtivo não resulta na ampliação da cidadania, mas na exploração da força de trabalho. Em muitos casos, contra as normas legais, as mulheres ainda continuam em posições de desvantagem em relação aos homens, por exemplo, na desigualdade salarial (Macedo e Santos, 2010). Com a volatilização do mercado de trabalho, a violência sobre as mulheres surge também em alguns setores políticos que buscam soluções na sua saída do trabalho produtivo; uma tentativa de acantonamento que não tem em conta os direitos de escolha, de autonomia económica e de realização profissional e pessoal. A participação num mundo do trabalho que não se adaptou à nossa entrada, e uma vida social que espera das mulheres que conciliem trabalho nos espaços público e familiar, sem os ajustes apropriados nesses mundos, constitui violência sobre as mulheres.

O apelo ao trabalho reprodutivo das mulheres, para a continuação da espécie, é acentuado num período em que a população da Europa envelhece. Alguns/umas políticos/as, entre outras entidades começam a entender o contributo insubstituível das mulheres. No entanto, não são dadas garantias nem de apoio a uma maternidade realmente compensadora nem de compensação das perdas na carreira, se «optarmos» por esse ato de generosidade social. Remato esta secção com a referência ao direito sobre os nossos corpos, e a ainda prevalecente criminalização social da interrupção voluntária da gravidez, apesar de alguns avanços legislativos, em quase toda a Europa. Estes exemplos ilustram como a limitação dos direitos produtivos e reprodutivos constitui violência sobre as mulheres.

A violência social constitui o cenário para a perpetração ilegítima do crime de violência por parceiros íntimos, que se discutre em seguida.

\section{Violência no espaço familiar na UE: Contornos da violência entre parcei- ros íntimos (VPI)}

Focaram-se aspetos da violência social sobre as mulheres, que têm sido pouco descritos como violência e nem sempre inseridos nas reclamações por jus- 
tiça social. Este ponto refere aspetos da violência sobre as mulheres, frequentemente aglomerados sob a designação violência «doméstica»; um termo depreciativo associado a ideias naturalizadas de «domesticidade» e subordinação. Reiteramos que as diferentes formas de violência muitas vezes se entrelaçam e reforçam entre a arena social mais ampla e o espaço social mais restrito da família. $\mathrm{O}$ cenário fornecido pela violência social abre espaço à violência entre parceiros íntimos (VPI) e, de alguma forma, contribuí para a sua indevida legitimação.

Este ponto e o que segue refletem sobre documentos-chave que incorporam a VPI na UE e em Portugal, mostrando a crescente conscientização e processos legislativos, na busca de resolução deste problema que afeta mulheres e homens e mina uma experiência humana mais democrática. Os dados Europeus acentuam a falta de soluções eficazes, em acumulação com a dificuldade de articular os atos legislativos e a ação humana no quotidiano (Macedo e Santos, 2010).

De forma alarmante, o Report on Domestic Violence against Women and Victim Support in the 27 member states and Croatia, do European Institute for Gender Equality (EIGE, 2012) afirma que «a violência doméstica» continua a ser uma prática generalizada, escondida e pouco comunicada, e que nove em cada dez vítimas de violência entre parceiros íntimos são mulheres. Apesar da reflexão e ação política, o porblema está longe de estar resolvido. $\mathrm{O}$ mesmo relatório prevê que pelo menos uma em cada cinco mulheres será violada durante a vida. Este valor aproxima-se do atingido em finais dos anos 1990 nos EUA, onde 17,7 milhões de mulheres cerca de 1 em cada 6 - foram vítimas de ataque ou violação, a maioria não denunciada (Heath, Lynch, Fritch e Wong, 2013).

Estes e outros achados exigem medidas políticas urgentes para enfrentar o «autismo social preocupante» que prevalece entre alguns grupos com base na incomunicabilidade (Macedo, 2009). Registando algum «progresso» no confronto ao problema, o relatório EIGE reconhece a extensa gama de dificuldades de resposta na EU e um investimento insuficiente - da UE e dos Estados-Membros. A falta e distribuição desigual de serviços especializados para mulheres maltratadas, e de formação específica para profissionais que lidam com vítimas e perpretadores, bem como a «inconsistência» dos programas são os principais problemas.

Delineia-se a necessidade de serviços diversos e estrategicamente localizados, investimento na contratação e treino de profissionais para apoiar vítimas e perpetradores; opção que ajudaria a repensar programas que tenham em conta a natureza delicada do problema, a sua dimensão social, e também os problemas individuais enfrentados por cada sujeito em violência, mulher ou homem, vítima ou agressor.

Do ponto de vista legal e com base no relatório do Instituto Europeu para a Igualdade de Género (EIGE, 2012) verifica-se uma taxa de condenação «baixa» para os casos registados, que raramente funciona como impedimento. Torna-se clara a necessidade de uma justiça mais ágil e eficiente, capaz de responder às necessidades sociais neste domínio e que desperte para outras formas de «condenação» 
da pessoa que comete o crime. Estas devem incluir atividades socialmente úteis, supervisionadas e suficientemente penalizadoras, como trabalho comunitário, e não apenas a erradicação na prisão, cujos «benefícios» para o sujeito e para a sociedade são questionáveis. A imersão no mundo do crime, também no interior do sistema prisional, mais do que "curar» pode levar o sujeito a processos de desumanização ligados a auto-desvalorização e raiva; podendo induzir à reprodução do crime de violência e a outras formas de criminalidade.

No que respeita às estruturas de apoio às vítimas, o relatório alerta que apenas oito Estados-Membros e a Croácia fornecem pelo menos um centro ou serviço de aconselhamento por cada 50000 mulheres; número insuficiente e ainda aquém na maioria dos Estados. Além disso, nos 27 Estados-Membros, apenas 17 prestam apoio às vítimas, e em seis, as linhas de apoio são gratuitas e 24 horas por dia. De forma igualmente alarmante, apenas cinco Estados-Membros oferecem uma casa abrigo para cada 10000 mulheres e apenas sete têm cobertura nacional, apesar do abrigo a mulheres vítimas de violência entre parceiros íntimos se dizer generalizado.

A incapacidade dos Estados para cuidar das mulheres vítimas de violência regista-se também na prevalência de uma política que penaliza a vítima. As mulheres são retiradas de casa, dada a incapacidade dos serviços para preservar o seu bem-estar e muitas vezes as suas vidas face ao agressor. Nesses casos, os autores permanecem em casa, aproveitam as suas rotinas diárias, enquanto as mulheres, traumatizadas e muitas vezes acompanhadas por filhas/os igualmente traumatizados, têm que enfrentar uma tripla violência: a agressão sobre elas e sobre as crianças/jovens; a remoção do seu modo e ritmos de vida habituais; o isolamento de parentes que poderiam apoiá-las. Estas formas combinadas de violência sobre as mulheres podem resultar em perda identitária, devido à perda de laços e de rotinas, podendo conduzir a sentimentos de desumanização e impotência. Estas tornaram-se questões candentes em discussões académicas recentes. Por exemplo, Maria Galano, Erin Hunter, Kathryn Howell, Laura Miller e Sandra Graham-Bermann (2013) fornecem uma análise detalhada sobre casas-abrigo para mulheres vítimas de violência entre parceiros íntimos em que identificam um conjunto de «despoletadores» que as mulheres têm que enfrentar quando deixam os parceiros e também o potencial e limites desses abrigos.

Esta secção destacou as deficiências do trabalho e políticas para proteger as mulheres vítimas de VPI, conforme registado pelo EIGE. Apesar da inadequação e insuficiência, os Estados têm procurado soluções. É deste esforço que tento dar conta em seguida, tomando o caso português a título de ilustração. A secção começa com a partilha de alguns dados e ilustra a ação de entidades do Estado ou financiadas por este, bem como a de Organizações Não Governamentais (ONG) que trabalham de forma autónoma com parcos recursos. 


\section{Enfrentando a violência no espaço familiar em Portugal: o caso da violên- cia entre parceiros íntimos (VPI)}

Um longo caminho tem sido percorrido, do ponto de vista legal desde a produção em 1991, da primeira lei de proteção das vítimas de violência, até à ainda recente criminalização, com implicações paradigmáticas fundamentais no confronto a este problema. Busca-se, atualmente, uma abordagem baseada na colaboração inter-institucional, através de parcerias entre os órgãos da Administração e a sociedade civil, que se dirige à busca de maior eficiência do sistema de apoio na proteção da vítima e na responsabilização do agressor. Esta orientação na resposta à violência doméstica corresponde à passagem de uma intervenção em cadeia, em que cada instituição atua isoladamente, com recurso ao encaminhamento da vítima entre serviços, pontualmente responsáveis pela intervenção, para uma intervenção mais holística, de corresponsabilização entre todos os serviços e profissionais que intervêm no processo. Esta intervenção em parceria, de cariz mais local, tem por objetivo uma maior capacidade na proteção dos direitos e no aumento da segurança das vítimas bem como na responsabilização dos agressores (Costa, 2009).

Como assume a Plataforma de Pequim, a violência sobre as mulheres é um obstáculo à igualdade, ao desenvolvimento e à paz, viola os direitos humanos e as liberdades fundamentais de mulheres e homens, sendo essencial a sua total erradicação. Considerando como preocupação para os Estados o fracasso na proteção e promoção dos direitos e liberdades, a Plataforma alerta para a tomada de consciência sobre as suas causas e consequências, incidência e medidas para combatê-la. A Plataforma desvenda também a situação de abuso físico, sexual e psicológico de mulheres e jovens, em diferentes sociedades, e associadas ao seu baixo estatuto social e económico (Declaração de Pequim e Plataforma de Acção, 1995).

Na mesma linha, Madeleine Adelman, Hillary Haldane e Jennifer R. Wies (2012) sublinhando como a cultura tem sido usada para defender, explicar ou desculpar a violência de género, e como barreira para a sua eliminação, mostram como aquela pode ser usada estrategicamente na luta contra a violência de género, por meio da mobilização consciente. Referiu-se já o trabalho de Jinan Usta, Nisrine Makarem e Rima Habib (2013) no que concerne o abuso económico.

Como na maioria dos Estados-Membros, em Portugal o problema da VPI está longe de ser resolvido. De acordo com a Associação Portuguesa de Apoio à Vitima (APAV) (2012), entre 2000 e 2011, 76582 vítimas recorreram a essa instituição. Cerca de 90\% (68751) mulheres vítimas de VPI e cerca de 90\% (68770) perpetradores masculinos. Apontando a crescente proeminência do problema, a APAV sublinha que, até 2011, foram feitas 20125 queixas às autoridades policiais. Este número é particularmente preocupante quando se sabe que muitos dos crimes não são relatados, por circunstâncias inerentes à relação de poder desigual entre agressor e vítima. Além disso, na maioria dos casos de violência no espaço familiar, vítima e agressor tinham um relacionamento conjugal (39352 casos) (http://apav.pt/), número que pode relacionar-se com a prevalência do pensa- 
mento religioso convencional, de mãos dadas, no passado, com o autoritarismo do Estado, para garantir a subordinação e silenciamento da cidadania, particularmente das mulheres.

Perante este panorama devastador, em consonância com a Declaração de Pequim e face à mobilização e orientações europeias, em que a igualdade de género tem vindo a assumir centralidade, tem vindo a ser desenvolvida em Portugal extensa pesquisa que foca género e violência de género. Foram também lançados vários atos legislativos, que estabelecem os parâmetros legais para confrontar o problema. Duarte (2012) explora esta questão de forma muito completa e detalhada. Neste artigo, dá-se visibilidade às mais relevantes para a discussão, sem preocupação de exaustividade. O Artigo 152 do Código Penal (Lei n.. 59/2007) trata do crime de violência «doméstica» de forma autónoma e estende o seu alcance e o Decreto-Lei n.ำ 201/2007 (com a Ordem n.. 20509/2008) prevê a isenção de taxas moderadoras para o acesso pelas vítimas ao Serviço Nacional de Saúde. Por sua vez a Lei n. ${ }^{\circ}$ 104/2009 melhora os mecanismos de suporte financeiro imediato a vítimas de violência «doméstica» e a Lei n.o 112/2009 estabelece o regime jurídico aplicável à prevenção.

Revelando também o esforço do Estado na luta contra este drama individual e social, o IV Plano Nacional Contra a Violência Doméstica (PNCVD) está atualmente em vigor como «instrumento de política fundamental». Amplia as preocupações de governos anteriores, traça as intenções do governo e enquadra-se na tentativa de modernização do Estado, juntamente com a ampliação da cidadania de mulheres e homens e a busca de igualdade na realização dos seus direitos humanos. O plano defende «o combate à violência doméstica, no aspeto jurídico-penal, na protecção das vítimas e na prevenção da violência doméstica e de género» (DR, 2010: 5763).

Fortalecer uma perspetiva integrada e holística deste problema, que decorre principalmente da assimetria estrutural de poder entre homens e mulheres, é a primeira orientação estratégica do PNCVD (DR, 2010), na sequência do plano anterior (2007-2010), que já reconhecia a necessidade de transversalidade de soluções. Embora a violência «doméstica» atingisse também outros grupos em situação de fragilidade, crianças, idosos, pessoas dependentes e portadoras de deficiência, o III Plano admitia serem as mulheres as maiores vítimas - violência de género (DR, 2007). O II Plano (2003-2006) focava particularmente a «violência doméstica contra as mulheres» (DR, 2003: 3867). Baseava-se na ideia de que a «falta de credibilidade social», atribuída aos seus testemunhos, o sentimento de impotência diante da violência, e a falta de confiança na proteção jurídica poderia levá-las de vítimas a perpretadores. Surgindo no âmbito do 50. o aniversário da Declaração Universal dos Direitos Humanos, o I Plano de Combate à Violência Doméstica salientou que esta questionava a ideia do igual valor e dignidade de cada ser humano (DR, 1999). Como consequência, o documento traçou um conjunto de metas e medidas de sensibilização, prevenção e intervenção, e investiu em pesquisa e estudo para proteger as vítimas. 
Na linha da ação legislativa para a igualdade, a Comissão para a Cidadania e Igualdade de Género (CIG) incide sobre a violência doméstica, de par com problemas como o tráfico de pessoas e a mutilação genital feminina. Sob supervisão direta da Presidência do Conselho de Ministros, a CIG tem desempenhado um papel crucial, ao contribuir para uma formulação jurídica dirigida à implementação de medidas práticas que causam mudanças reais na vida de muitas mulheres e homens (http://www.cig.gov.pt/). Na tentativa de apoiar a superação das deficiências detetadas a nível da UE, a CIG proclama que o estabelecimento de uma sociedade mais igualitária e mais justa depende da luta contra a violência doméstica; o que levou ao estabelecimento de um conjunto de políticas concertadas e estruturadas: de proteção à vítima e de condenação dos perpretadores; de identificação e de prevenção do fenómeno; de qualificação e formação de profissionais e de provisão de serviços e estruturas. Sendo a sua ação muito ampla, dou relevo às campanhas de sensibilização contra a violência «doméstica», dirigidas a atores particulares e à população em geral.

Em 2005, acentuava-se «Uma destas 3 mulheres é vítima de violência, a solução passa por si» com base em dados da Pesquisa Nacional da Vitimização. Em 2006, a campanha buscou implicar os homens na recusa de comportamentos de violência, com o apelo «Não insulte, não humilhe», por outro lado, responsabilizava para a denúncia, acentuando «A violência doméstica é crime. Denuncie». Já a campanha de 2008, claramente dirigida a jovens, mostrava a contradição entre amor e violência e apelava ao fim da violência no namoro, um problema crescente.

Outras organizações têm estado envolvidas na luta contra a violência «doméstica» e a VPI, e em favor dos direitos das mulheres, refiro apenas algumas sem desvalorizar outras cujo trabalho não é mencionado. A União de Mulheres Alternativa e Resposta (UMAR) lida diretamente com a VPI, e tem sido crucial no apoio às mulheres vítimas, por meio de projetos e da criação de casas-abrigo (Magalhães, Afonso, Ruiz, Monteiro, Ribeiro e Ribeiro, 2012). Por sua vez, a Associação de Mulheres Contra a Violência (AMCV), conglomera um conjunto de associações que trabalham diretamente para apoiar vítimas a vários níveis, incluindo VPI. Como parte de um grupo multinacional, a Soroptimist Portugal procura melhorar as vidas de mulheres e raparigas, através de campanhas contra a violência, especificamente no namoro, e patrocinando os seus caminhos educacionais.

A Associação Portuguesa de Estudos sobre as Mulheres (APEM) constitui um instrumento de empoderamento ao dar visibilidade às questões de género, numa articulação entre produção científica e preocupação social (http://www.apemestudos.org/ ). Também a Associação ESPAÇOS: Projetos Alternativos de Mulheres e Homens incide na prevenção, trabalhando para a (re)construção do espaço social através do diálogo entre mulheres e homens. Busca um paradigma «novo» de autenticidade, reconhecimento e democracia, sem espaço para qualquer forma de violência (http://associacaoespacos.blogspot.pt/). Alguns/mas estudiosos/as têm-se também debruçado sobre desigualdades de género, violência, VPI e pro- 
blemas relacionados, desocultando e buscando soluções, e introduzindo a produção científica das mulheres no pensamento da Academia. Refiro por último o papel, pouco visibilizado, de coletivos e movimentos sociais, particularmente de jovens, que têm tomado estas questões nas suas mãos e trabalhado para a melhoria do espaço social.

\section{Para a utopia viável de uma vida não violenta e amiga-de-mulheres-e- -homens}

Reconhecer a heterogeneidade intragrupal das mulheres implica recusar perspetivas de bem comum universal, que substimam as diferenças. Para promover a discussão política, a tomada de decisão e a cooperação, na resolução de problemas como a violência sobre as mulheres, há que ter em consideração a experiência, necessidades e interesses das pessoas envolvidas, o que requer formas diferenciadas de inclusão. No que diz respeito à VPI, isto implica a criação de espaços acolhedores e não ameaçadores onde as mulheres sintam liberdade para se expressar e saibam que vão receber apoio adequado.

Estas preocupações podem ser identificadas em alguma produção legislativa a nível europeu e dos Estados-Membros. Usou-se o exemplo português. Uma visão mais ampla, sugere a necessidade de produção legislativa a nível global, baseada na escuta de mulheres e homens, através de uma escala ascendente de comunicação (Young, 2002), que projete voz e cidadania (Lister, 2007). Isto poderá abrir caminho à rutura com hábitos culturais profundamente enraizados que frequente e extensivamente minam os direitos humanos de muitas mulheres (e homens).

Como se ilustrou com alguns exemplos, diferentes entidades desempenham um papel crucial nesta luta. Relações de proximidade com as pessoas podem gerar ações mais apropriadas, uma intervenção mais centrada, e uma resolução casuística dos problemas, agindo sobre causas e sobre sintomas.

Além de uma justiça mais ágil e eficiente, e trazendo à cena outros atores, o papel crucial dos órgãos estatais também deve ser enfatizado, incluindo o fornecimento de recursos de prevenção e remediação, a criação de serviços, formação e desenvolvimento de programas para lidar com vítimas e agressores.

Reconhecimento e legitimidade são as principais condições para um paradigma «novo» da vida como exercício de direitos, incluindo o direito da responsabilidade social. Horizontalidade na construção da identidade e da cidadania em parceria com outros, pela construção de um diálogo efetivo entre entidades de igual valor e pela partilha equitativa do trabalho produtivo e reprodutivo, juntamente com uma reconciliação social mais flexível amiga-de-mulheres-e-homens completam esse cenário.

Movimentos de resistência «novos» inclusivos de-mulheres-e-homens, constituem ferramentas importantes para enfrentar a insegurança com que nos confrontamos, e na busca de formas de vida «novas», em que as identidades de 
género e diferentes orientações afetivas sexuais possam constituir felicidade e realização pessoal.

Este paradigma «novo» implica a eliminação de todas as formas de violência social, seja de género, "classe», etnia, capacidade, religião, língua, cultura... Além das medidas mencionadas, a erradicação de todas as formas de violência pode emergir da construção deste mundo de utopia viável (Freire, 1992); um duro, longo, processo cuja magnitude reclama mobilização.

\section{Para concluir}

Este artigo explorou violência(s) sobre as mulheres, referindo a violência entre parceiros íntimos. $\mathrm{O}$ argumento principal está na necessidade de revelar, prevenir e remediar as violência(s) para - e por meio da - construção de formas de vida não-violentas, amigas-de-mulheres-e-homens, levando à formulação de uma democracia «outra» mais autêntica e inclusiva. Constituindo formas de violência que mitigam a cidadania, torna-se urgente revelar e eliminar as situações de impotência, falta de espaço para expressar e fazer ouvir a nossa voz, bem como as condições de falta de recursos e de acesso a bens essenciais que estão, muitas vezes, no centro da infelicidade humana e da falta de realização pessoal, podendo conduzir à violação ilegítima do outro/a mais frágil.

Sendo a violência social e a VPI um problema e também um sintoma individual e social de questões mais profundas, exige uma ação concertada a vários níveis com contribuição de diferentes entidades. Isto implica: i) revelar e reconhecer as diferentes formas que a violência sobre as mulheres pode tomar; ii) remediar a manifestação do problema, abordando os seus sintomas - ação que se mantém no quadro do pensamento hegemónico atual; e iii) procurar as raízes do problema e das desigualdades intrínsecas que o paradigma hegemónico tem conseguido ocultar - ação que corresponde a um paradigma «novo» de reconhecimento e legitimação.

\section{Referências}

AAVV (1998), «Mulheres Vítimas de Maus Tratos na Conjugalidade», in Espaços, Revista de Educação Social, Instituto Superior de Ciências Educativas, Gabinete de Apoio e Projectos de Educação Social.

Adams, Adrienne E.; Tolman, Richard M.; Bybee, Deborah; Sullivan, Cris M.; Kennedy, Angie C. (2012), «The impact of intimate partner violence on low-income women's economic well-being: The mediating role of job stability», Violence Against Women, $18,12,1345-1367$.

Adelman, Madelaine; Haldane, Hillary; Wies, Jennifer R. (2012), «Mobilizing culture as an asset: A transdisciplinary effort to rethink gender violence», Violence Against Women, $18,691-700$. 
Arnold, Gretchen; Ake, Jami (2013), «Reframing the narrative of the battered women's movement», Violence Against Women, 19, 5, 557-578.

Auchter, Bernard; Backes, Bethany L. (2013), «NIJ's program of domestic violence research: Collaborative efforts to build knowledge guided by safety for victims and accountability of perpetrators», Violence Against Women, 19, 6, 713-736.

Auchter, Bernard; Moore, Angela (2013), «Mounting and sustaining the violence against women research and evaluation program at the national institute of justice», Violence Against Women, 19, 6, 687-712.

Azambuja, Mariana; Nogueira, Conceição (2008), «Introdução à violência contra as mulheres como um problema de direitos humanos e de saúde pública», Saúde e Sociedade, $17,3,101-112$.

Baker, Carrie (2008), The Women's Movement Against Sexual Harassment, New York: Cambridge University Press.

Beijing Declaration and Platform for Action (1995), The Fourth World Conference on Women, [em linha] disponível em http://www.cite.gov.pt/asstscite/downloads/universais/Beijing Declaration and Platform for Action.pdf/ [consultado em $12 \mathrm{de}$ junho de 2013].

Bernstein, Basil (1996), Pedagogy, symbolic control and identity: Theory, research and critique, Bristol, Taylor \& Francis.

Brewer, John (2004), «Imagining the sociological imagination: The biographical context of a sociological classic», The British Journal of Sociology, 55, 3, 317-333.

Campos, Carmen (2004), «Justiça consensual, violência doméstica e direitos humanos», in Marlene Neves Strey, Mariana Azambuja e Fernanda Pires Jaeger, (org.), Violência, gênero e políticas públicas, Porto Alegre, EDIPUCRS, pp. 63-84.

Caridade, Sónia; Machado, Carla (2006), «Violência na intimidade juvenil: Da vitimação à perpetração», Análise Psicológica, 4 (XXIV), 485-493.

Casimiro, Cláudia (2013), «Violência feminina: a face oculta da violência no casal», Sociologia online, Revista da Associação Portuguesa de Sociologia, 6, 5-25, [em linha] disponível em http://revista.aps.pt/cms/files/artigos pdf/ART51b72dfd06645.pdf [consultado em 2 de fevereiro de 2015].

Costa, Dália (2009), «Uma mudança de paradigma na intervenção social na violência doméstica: os casos de parcerias em Portugal», Sociedade em Debate, 15, 1, 147-164.

Decreto-Lei 201/2007, Diário da República, 1. ํㅜ série, n. $\stackrel{\circ}{ } 100$.

Diário da República (DR) (1999), Plano Nacional Contra a Violência Doméstica (1999-2002).

Diário da República (DR) (2003), II Plano Nacional Contra a Violência Doméstica (2003-2006).

Diário da República (DR) (2007), III Plano Nacional Contra a Violência Doméstica (2007-2010).

Diário da República (DR) (2010), IV Plano Nacional Contra a Violência Doméstica (2011-2013).

Dias, Isabel (2010), «Violência doméstica e justiça», Sociologia,20, 245-262.

Duarte, Madalena (2012), «O lugar do Direito nas políticas contra a violência doméstica», ex aequo,25, 59-73.

European Institute for Gender Equality (EIGE) (2012), Support services for women victims of domestic violence in the EU Member States and Croatia, [em linha] disponível em http:/ / eige.europa.eu/content/document/ fact-sheet-support-for-women-victimsof-intimate-partner-violence [consultado em 4 de março de 2013].

Felker, Reginald (2006), O dano moral, o assédio moral e o assédio sexual nas relações do trabalho: doutrina, jurisprudência e legislação, São Paulo, LTr.

Ferreira, António (2005), Acesso ao Direito e Mobilização dos Tribunais de Trabalho: o caso da discriminação entre mulheres e homens, Lisboa, Comissão para a Igualdade no Trabalho e no Emprego. 
Freire, Paulo (1992), Pedagogia da esperança, Rio de Janeiro, Paz e Terra.

Freitas, Maria Ester (2001), «Assédio moral e assédio sexual: faces do poder perverso nas organizações», Revista de Administração de Empresas, 41, 2, 8-19.

Galano, Maria; Hunter, Erin; Howell, Kathryn; Miller, Laura; Graham-Bermann, Sandra (2013), «Predicting shelter residence in women experiencing recent intimate partner violence», Violence Against Women, 19, 4, 518-535.

Gonçalves, António (1985), "A simbolização da violência social», Revista da Faculdade de Letras - Geografia, 1, 1, 35-45.

Heath, Nicole; Lynch, Shannon; Fritch, April; Wong, Maria (2013), «Rape myth acceptance impacts the reporting of rape to the police: A study of incarcerated women», Violence Against Women, 19, 9, 1065-1078.

Hequembourg, Amy; Livingston, Jennifer; Parks, Kathleen (2013), «Sexual victimization and associated risks among lesbian and bisexual women»Violence Against Women, $19,5,634-657$.

Koning, Marijke (2005), Lugares emergentes do sujeito-mulher, viagem com Paulo Freire e Maria de Lourdes Pintasilgo, Porto, Edições Afrontamento.

Lei 104/2009, Diário da República, $n .^{\circ}$ 178, $1 .^{\underline{a}}$ série.

Lei 112/2009, Diário da República, $n .^{\circ} 180,1 .^{\underline{a}}$ série.

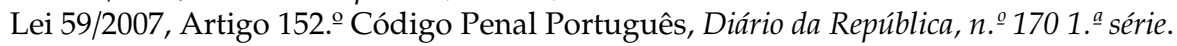

Lisboa, Manuel; Barroso, Zélia; Marteleira, Joana (2003), O contexto social da violência contra as mulheres detectada nos Institutos de Medicina Legal, Lisboa, CIDM.

Lisboa, Manuel; Vicente, Luísa; Carmo, Isabel do; Nóvoa, António (2003), Os custos sociais e económicos da violência contra as mulheres: Sintese dos resultados do inquérito nacional 2002, Lisboa, CIDM.

Lisboa, Manuel; Vicente, Luísa; Barroso, Zélia (2005), Saúde e violência contra as mulheres: Estudo sobre as relações existentes entre a saúde das mulheres e as várias dimensões de violência a que tenham sido vítimas, Lisboa, Direcção Geral da Saúde.

Lister, Ruth (1997), Citizenship: Feminist perspectives, Nova Iorque, New York University Press.

Lister, Ruth (1999), «Promoting women's economic independence», in Geoff Dench (ed.), Rewriting the sexual contract, New Brunswick, Transaction Publishers, pp. 180-191.

Lister, Ruth (2007), «Inclusive citizenship: Realizing the potential», Citizenship Studies, 11, $1,49-61$.

Lopez, Vera; Chesney-Lind, Meda; Foley, Julia (2012), «Relationship power, control, and dating violence among latina girls», Violence Against Women, 18, 6, 681-690.

Lourenço, Nelson; Lisboa, Manuel; Pais, Elza (1997), Violência contra as mulheres, Lisboa, CIDM.

Lourenço, Nelson; Lisboa, Manuel (1991), Representação de violência, Lisboa: Ministério da Justiça.

Macedo, Eunice (2012a), School rankings on the other hand... possibilities of young adult citizenship in the tension of educational and social change, Tese de doutoramento, Faculdade de Psicologia e de Ciências da Educação da Universidade do Porto, Porto, Portugal.

Macedo, Eunice (2012b), «(Re)constructing femininities and masculinities: Northern Portuguese students speak about their lives, desires and dreams», Educação, Sociedade e Culturas, 35, 67-88.

Macedo, Eunice (2009), Cidadania em confronto: Educação de elites em tempo de globalização, Porto, CIIE/Livpsic.

Macedo, Eunice; Santos, Sofia (2009), «Apenas mulheres? Situação das mulheres no mercado de trabalho em quatro países europeus», Ex aequo, 19, 129-155. 
Macedo, Eunice; Santos, Sofia (2010), «Still in between paid and unpaid work?: Women's discussion about their situation in Belgium, Lithuania, the Netherlands and Portugal», Gender Studies and Research, 8, 59-69.

Macedo, Eunice; Araújo, Helena C. (2009), «Liderança das mulheres: Masculinidade(s) e feminilidade(s) em contextos socio-educativos e relações de poder», in Eunice Macedo e Marijke de Koning (coords.), ReInventando lideranças: Género, educação e poder, Porto, Fundação Cuidar O Futuro/Livpsic, pp. 101-116.

Machado, Carla; Matos, Marlene; Moreira, A. I. (2003), «Violência nas relações amorosas: Comportamentos e atitudes na população universitária", Psychologica, 33, $69-83$.

Magalhães, Maria José (2010), «A arte e a violência no olhar: Activismo feminista e violência contra as mulheres», Revista Crítica de Ciências Sociais, 89, 89-109.

Magalhães, Maria José (2012), «Construção do sujeito mulheres: Subjectividades das vozes e dos silêncios», in Rosa Nunes, Maria José Magalhães \& Angélica Lima Cruz (coords.), Pelo fio se vai à meada: Percursos de investigação através de histórias de vida, Lisboa, Ela por Ela, pp. 25-51.

Magalhães, Maria José; Afonso, Ilda; Ruiz, Lídia; Monteiro, Isabel; Ribeiro, Vanessa; Ribeiro, Liliana (2012), "The intervention of UMAR in the area of violence against women», Interdisciplinary Journal of Family Studies, 17, 1, 169-179.

Monteiro, Fátima Jorge (2005), Mulheres agredidas pelos maridos: De vítimas a sobreviventes, Lisboa, ONGs do Conselho Consultivo da CIDM.

Neves, Sofia (2008), Amor, poder e violências na intimidade, Coimbra, Quarteto.

Paiva, Carla; Figueiredo, Bárbara (2004), «Abuso no relacionamento íntimo: Estudo de prevalência em jovens adultos portugueses», Psychologica,36, 75-107.

Rivas, Carol; Kelly, Moira; Feder, Gene (2013), «Drawing the line: How African, Caribbean and white British women live out psychologically abusive experiences», Violence Against Women, 19, 9, 1104-1132.

Usta, Jinan; Makarem, Nisrine; Habib, Rima (2013), «Economic abuse in Lebanon: Experiences and perceptions», Violence Against Women, 19, 3, 356-375.

Young, Iris (1997), Intersecting voices: Dilemmas of gender, political philosophy, and policy, Princeton, Princeton University Press.

Young, Iris (2002), Inclusion and democracy, Oxford, University Press.

Eunice Macedo. Doutorada, investigadora integrada do CIIE; desenvolve o seu Pós Doutoramento na equipa do projeto internacional «Reducing Early School Leaving in the EU». Co-coordenadora do Projeto "Construindo Pilares do Projeto Europeu com Educação, Cultura e Cidadania». Preside à Associação ESPAÇOS e está na direção do Instituto Paulo Freire de Portugal. Tem participado no debate académico nacional e internacional com comunicações e publicações nas suas áreas de interesse - cidadania, género e educação. eunicemacedo 58@hotmail.com

Artigo recebido em 30 de setembro de 2014 e aceite para publicação em 24 de fevereiro de 2015. 